\title{
The laparoscopic Nissen fundoplication is a safe and effective treatment of the pathological acid and bile gastroesophageal reflux in the elderly
}

\author{
A Brillantino*, L Monaco, M Schettino, F Torelli, G Izzo, A Cosenza, \\ L Marano, R Porfidia, G Reda, F Foresta, P Maglione and N Di Martino
}

Address: VIII Division of General Surgery, Second University of Naples, Italy

* Corresponding author

from XXI Annual Meeting of The Italian Society of Geriatric Surgery

Terni, Italy. 4-6 December 2008

Published: I April 2009

BMC Geriatrics 2009, 9(Suppl I):A89 doi:10.1 186/I47|-23I8-9-SI-A89

This abstract is available from: http://www.biomedcentral.com/I47I-23 I8/9/SI/A89

(c) 2009 Brillantino et al; licensee BioMed Central Ltd.

\begin{abstract}
Aim
The influence of age in the choice of treatment for gastroesophageal reflux disease (GERD) is still debated. In summary, although the laparoscopic antireflux surgery is generally undertaken with some hesitation in the elderly and the total fundoplication is considered an obstacle in presence of defective peristaltic activity, some authors recently showed good clinical outcome and low morbidity in the older GERD patients treated by laparoscopic $360^{\circ}$ fundoplication.
\end{abstract}

This study aimed to compare the clinical outcome of the younger with the older patients undergone laparoscopic antireflux surgery for chronic GERD.

\section{Methods}

Fifty-seven consecutive patients underwent laparoscopic Nissen fundoplication for GERD. Thirty-two patients were younger than 65 years (Group I) and twenty-five were more than 65 years old (Group II). Before and one year after fundoplication all the patients underwent symptom questionnaires, upper gastrointestinal endoscopy, esophageal manometry and combined $24 \mathrm{~h}$ esophageal $\mathrm{pH}$ and bilirubin monitoring.

\section{Results}

The prevalence of atypical symptoms and hiatal hernia was higher in the elderly patients, compared to the younger group ( $60 \%$ vs $32 \% ; 80 \%$ vs $68 \%$ : $\mathrm{p}<0.05)$. The older patients showed more often than younger severe esophagitis and impaired esophageal peristalsis (44\% vs $27 \%$; $60 \%$ vs $32 \%$ : $\mathrm{p}<0.05$ ). Pathological esophageal bile exposure was more common among the elderly ( $88 \%$ vs $68 \%$ ), in contrast with the abnormal acid exposure that was similar for the two groups. The operation time and the incidence of intraoperative and postoperative complications didn't differ significantly between the two groups. The median hospitalization time was 3 days in each group. At follow-up none of the enrolled patients showed GERD symptoms. Mild esophagitis was found only in two patients which preoperatively showed severe esophageal mucosal damage. The combined 24-h esophageal $\mathrm{pH}$ and bilirubin monitoring showed the normalization of both acid and bile reflux in the two groups.

\section{Conclusion}

Our results suggest that age doesn't affect the outcome of laparoscopic Nissen fundoplication. The antireflux surgery represents a safe and effective treatment for GERD, either in the young or in the elderly patients, achieving good results in improving symptoms, healing esophagitis and suppressing both acid and bile reflux. 